\title{
Energy savings due to building insulation of different thickness
}

\author{
Tadeusz Orzechowski ${ }^{1, *}$, and Mateusz Orzechowski ${ }^{2}$ \\ ${ }^{1}$ Kielce University of Technology, Al. Tysiąclecia PP 7,25-314 Kielce, Poland \\ ${ }^{2}$ Statistical Office in Kielce, Wróblewskiego 2, 25-369 Kielce, Poland
}

\begin{abstract}
In the plans of thermo-modernisation of historic buildings, strict requirements on energy performance are often relaxed. Detailed analyses are performed to select thermal upgrading technology that would ensure maximum environmental benefits while preserving the historic value of the building. The analysis of the costs of thermal upgrading with the use of heat-preserving plasters having different insulation properties is made for a coal-fired boiler plant. Optimal and advantageous ranges of insulation materials application are shown in reference to coal savings in boilers with variable and constant efficiency. Climatic conditions and environmental benefits are indicated.
\end{abstract}

\section{Introduction}

Big cities have to cope with poor quality of ambient air, which is related to emissions from transport and heating. It is a particularly serious problem in urban areas with densely arranged old buildings, where heat is supplied by local coal-fired facilities. The actions of local governments aimed at substituting coal with less harmful fuels are not always effective. The reason for users' preference for coal are lower prices when compared with other energy carriers. Additionally, old buildings under supervision of conservation officers cannot be thermally upgraded using typical technologies that involve the external walls insulation retrofit by over-cladding. That would ruin the historic and architectural value of the building and the environment. When thermal upgrades of such buildings are prepared, strict requirements concerning the energy performance are often relaxed. Detailed analysis are made to choose such renovation solutions that would ensure maximum environmental protection and preserve historic heritage [1]. As a result, technologies selected to fit specific buildings generate higher costs. Therefore, it is necessary to seek funds that would allow the conservation of the possible largest historic environment and, at the same time, be acceptable to the public [2].

As regards materials for construction industry, an extremely wide rage of options are available. The descriptions of the materials can be found in literature, e.g. [3]. In study [4], a systematic approach to proper selection and identification of the best upgrading solutions for existing buildings is discussed, including those intended for reduction in energy consumption and greenhouse gases emissions. Historic buildings that are in various

\footnotetext{
* Corresponding author: todek@tu.kielce.pl
} 
condition, were constructed using different technologies and materials used at the times a given structure was built. Every time the building envelope upgrading is planned, it is necessary to check the chemical composition, or conduct an analysis of the materials that will be used [5], [6]. Investigations conducted in France indicate that energy consumption in old buildings is affected by their ambient surroundings: microclimate, location in the city and the area, shading, and others [7]. The envelope insulation has influence not only on energy consumption but also, indirectly, on $\mathrm{CO}_{2}$ emissions into the atmosphere. Authors of study [8] discuss multi-parameter optimisation analysis carried out with respect to economic and environmental criteria applied jointly. Heating costs also depend on external conditions of the building envelope, including the orientation with respect to the cardinal directions [9].

Taking into account all the constraints mentioned above, it is possible to make improvements in thermal properties of the envelope of historic buildings by installing insulation on the internal side. That reduces emissions into the atmosphere, even if the fuel for heating is not changed. Costs calculations and listing the optimal parameters of the prospective investment could become an encouragement for the users to choose thermal upgrading of that kind.

\section{Problem formulation}

In Poland, the material most frequently used to improve the insulation properties of the building envelope is foamed polystyrene. The reason is low price and popularity of this technology [10]. In some cases, the material can be used for internal insulation, but every time it is necessary to make detailed analysis of moisture passing through the building wall, and to check the ventilation quality with respect to moisture excess removal. To avoid risks mentioned above, it is necessary to apply different technologies that, as a rule, are more expensive. That affects return on investment, the accessibility of loan, etc. The application of a coat of plaster, which can be perlite-based, having enhanced insulation properties is one of currently recommended technologies. If plaster with the addition of pre-sorted granules is prepared on the site, thermal conductivity is approx. $0.15 \mathrm{~W} / \mathrm{mK}$. Perlite plaster mortars with thermal conductivity coefficient of $0.067 \mathrm{~W} / \mathrm{mK}$ are also available, but their price is almost twice higher. The same refers to other insulation materials.

When balancing thermo-modernisation, to seek for optimal solutions, it is necessary to achieve balance of total costs $C_{\mathrm{A}, \mathrm{N}}$, which contain heating costs and insulation placing costs, with the costs of necessary materials, which can be written as follows:

$$
C_{A, N}=\left(\frac{f_{1}}{R_{w}+d_{i n s} / \lambda_{i n s}}+U_{2} f_{2}\right) C_{E} \sum_{j=1}^{N b}\left(T_{i}-T_{e j}\right) \frac{\tau_{j}}{\eta_{1 j} \eta_{2 j}}+C_{N i}\left(d_{i n s} C_{i n s}+C_{d}\right)
$$

where $f_{1}$ and $f_{2}$ represent the shares of insulated and uninsulated (e.g. window openings) exterior closures, respectively, $R_{\mathrm{w}}$ and $d_{\text {ins }} / \lambda_{\text {ins }}$ is heat conductivity resistance of uninsulated enclosure and the insulation material with thickness $d_{\text {ins }}$ and heat conductivity $\lambda_{\text {ins. }} U_{2}$ is heat transfer coefficient of the uninsulated part. $C_{\mathrm{E}}, C_{\mathrm{Ni}}, C_{\mathrm{ins}}$ and $C_{\mathrm{d}}$ denote, respectively: energy costs, coefficient that refers to the cost of credit in the balanced period, insulation costs and insulation installing costs.

In old buildings that have not been modernised for various reasons, heating systems are often based on coal boilers, usually hopper-fed, operating in the systems without buffer storage tank. Boiler capacity is adjusted in accordance with the demand for heating power, which results from actual weather conditions. At such operational arrangement of the boiler, its efficiency $\eta_{1}$ changes with load at transmission efficiency $\eta_{2}$. The amount of heat necessary to maintain the designed temperature $T_{\mathrm{i}}$ is proportional to the appropriate 
temperature difference, and heat consumption is proportional to the time of temperature difference occurrence $\tau_{\mathrm{j}}$. In formula (1), it is assumed that the heating of the building starts when the external temperature $T_{\mathrm{e}}$ is lower than the base temperature $T_{\mathrm{b}}$ (hereafter adopted $T_{\mathrm{b}}=12{ }^{\circ} \mathrm{C}$ ). Its value allows to determine the number of intervals summation $\mathrm{N}_{\mathrm{b}}$ in Eq. (1).

If no external constraints or requirements (e.g. standard-specific ones) are found, the investment should be realised in accordance with criteria imposed to ensure optimal handling of the investment. Those criteria include the minimum total costs. From Eq. (1), it is necessary to calculate the minimum total costs with reference to the insulation thickness. The condition necessary for the occurrence of the extremum is the zero value of the total

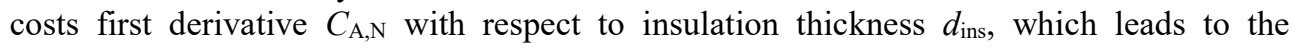
following expression:

$$
d_{\text {ins } \mathrm{Opt}}=\sqrt{\frac{\lambda_{i z} f_{1} C_{E} \sum_{j=1}^{N b}\left(T_{i}-T_{j}\right) \frac{\tau_{j}}{\eta_{1 j} \eta_{2 j}}}{C_{N i} C_{i n s}}}-\lambda_{\text {ins }} R_{w}
$$

Adopting a constant index of the annual fuel price increase $r_{E}$, the total costs of the required combustion of fuel $C_{\mathrm{E}}$ after $\mathrm{N}$ successive years can be calculated acc. the formula:

$$
C_{E}=\frac{\left(1+r_{E}\right)^{N}-1}{r_{E}} C_{E 1}
$$

$C_{\mathrm{E} 1}$ is the per-unit price of the fuel in the first year.

According to forecast given in [11], annual increase in coal prices for private consumers up to the year 2030 will be approx. 3\%. In study [12], over 2025 time horizon, this value is only about $1.35 \%$. For further calculations, the value is assumed to be $r_{\mathrm{E}}=2 \%$.

If the thermal upgrading investment is funded from a bank loan with fixed interest rate $i_{\mathrm{r}}$, the total repayment over $\mathrm{N}$ years is:

$$
C_{A, i n s N}=C_{A, i n s} C_{N i}=C_{A, i n s} N i_{r} \frac{\left(1+\frac{i_{r}}{12}\right)^{12 N}}{\left(1+\frac{i_{r}}{12}\right)^{12 N}-1}
$$

where $C_{\mathrm{A}, \text { ins }}=d_{\text {ins }} C_{\text {ins }}+C_{\mathrm{d}}$ (see Eq. 1).

\section{Results}

To calculate the total costs involved in thermo-modernisation investment, it is necessary to have a forecast of weather conditions for the term of the loan, or the investment amortisation period. Unfortunately, weather forecasts that cover time lengths longer than a month are highly unreliable. To be on the safe side, it is necessary to take into account average values obtained from long-term weather records, provided by Central Statistical Office of Poland [13], which are presented in Fig. 1. 


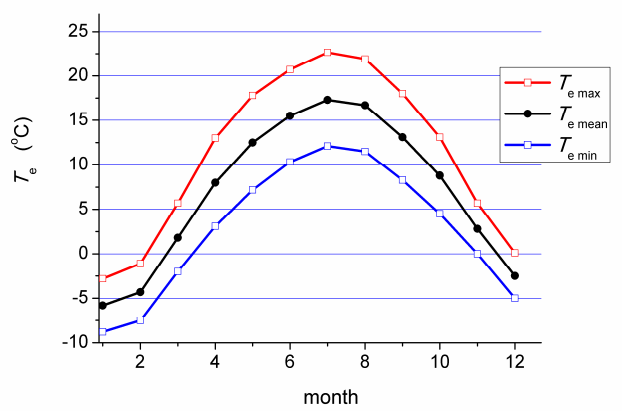

Fig. 1. Mean temperatures in Poland [13].

To account for the actual conditions during the heating season, the number of heating degree days (HDD) for a selected base temperature was determined from the Hitchin's formula [14]. Calculations were conducted for mean temperature values, shown in Fig. 2 while taking necessary constants into consideration [15].

Exemplary computations were conducted for the building wall of thermal resistance 0.5 $\mathrm{W} / \mathrm{mK}$ and two types of insulation materials. The first is the blend of separately purchased components mixed at the construction site $(\lambda \approx 0.15 \mathrm{~W} / \mathrm{mK})$. The other, manufactured at specialised production facilities, contains additives that enhance insulation properties $(\lambda=0.076 \mathrm{~W} / \mathrm{mK})$. Figure 2 shows changes in the optimal thickness of heat-preserving, perlite-based plaster as the term of the loan increases acc. Eq. 2.

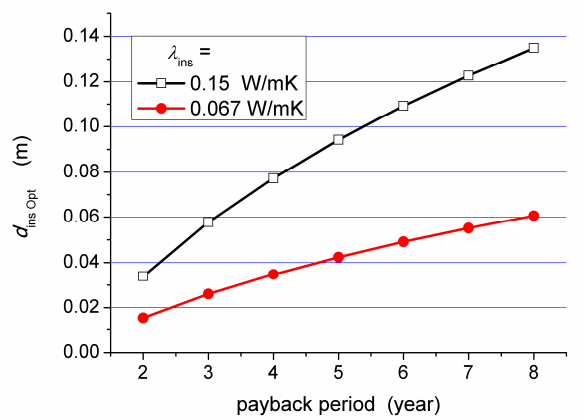

Fig. 2. Optimal thickness of the heat-preserving plaster over the term of the loan at $5 \%$ interest rate.

Calculations were made for the heating system with a coal-fired boiler, the efficiency of which depends on the load. Linear dependence is assumed, so at the minimal load, boiler efficiency is $20 \%$ and it grows until the $80 \%$ maximum value is reached at full load.

The thickness of the plaster with lower insulation properties, optimised with respect to total costs, is over twice as much as that of the other type of plaster, and the ratio of appropriate values shows, with good approximation, price relationship between those two. Also, it should be noted that a longer term of the loan makes it possible to apply a thicker insulation layer.

Changes in both components (i.e. costs of heating and insulation) of the total costs as a function of the plaster thickness is shown in Fig. 3. For a five-year term of the loan and fixed interest rate $i_{\mathrm{r}}=5 \%$, the optimal insulation thickness is $9.4 \mathrm{~cm}$, and the overall cost of thermal upgrading amounts to almost $142.5 \mathrm{PLN} / \mathrm{m}^{2}(1 \mathrm{USD} \approx 4 \mathrm{PLN})$. 


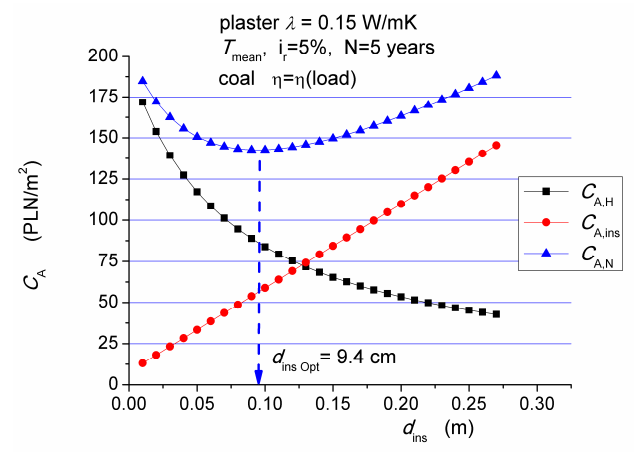

Fig. 3. Heating, insulation and total costs for coal heating system $(\lambda=0.15 \mathrm{~W} / \mathrm{mK})$.

Figure 4 shows total costs for the mean distribution of monthly temperatures in the heating season and also for extremes of temperatures: minimum and maximum ones in each month of the heating season. The dependences shown in Fig. 4 indicate considerable changes in costs caused by weather cycles and they can be used to assess the investment risk. The calculations show that as much as $30 \%$ deviation from the optimum thickness leads to only a few percent increase in total costs.

Poorly predictable weather conditions are a main risk factor for thermal upgrading investment. Figure 4 shows total costs of the investment for the assumption that average monthly temperatures take the extreme values as shown in Fig. 2. It is obvious that at milder temperatures during the heating season, costs are the lowest, and the highest at low temperatures. In the case under consideration, differences of a few percent are found.

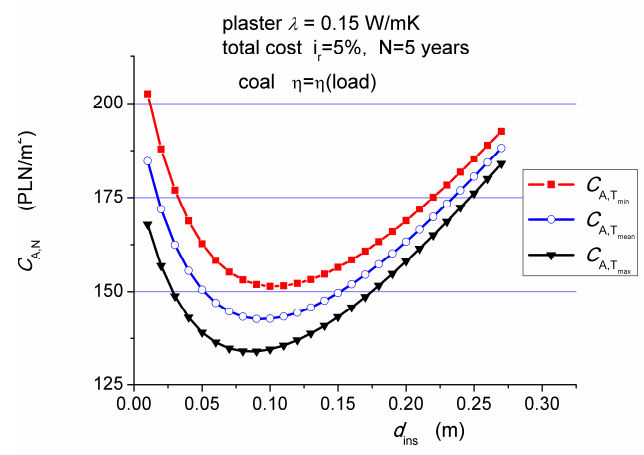

Fig. 4. Change in total costs for different plaster thicknesses under various climatic conditions.

The comparison of the total costs of thermo-modernisation with the use of a plaster coat having different insulation properties over a five-year term of the loan and fixed interest rate of $5 \%$ shows lower costs of thermal upgrading with plaster of lower coefficient of thermal conductivity for thinner layers. For a $6 \mathrm{~cm}$ thick layer, the costs are the same. As the layer thickness of the worse quality plaster grows, the costs are clearly lower, which is shown in Fig. 5. 


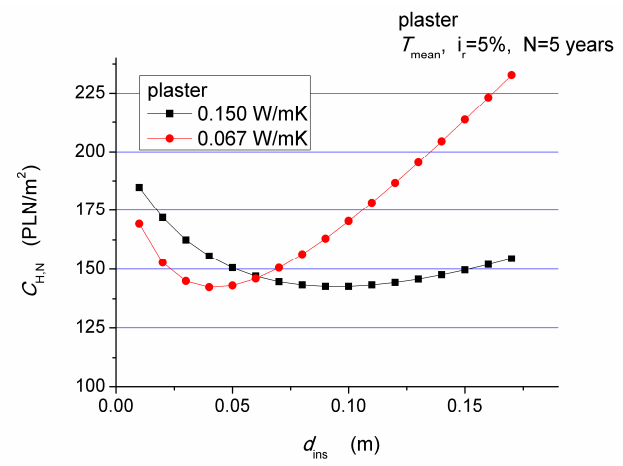

Fig. 5. Total costs of thermal upgrading with plaster having different insulation properties, depending on the clad layer thickness.

The most important environmental effect of insulation installing are savings in fuel consumption. That directly reduces carbon dioxide emissions into the atmosphere, equivalent particulates emissions, and also that of $\mathrm{SO}_{2}$ and $\mathrm{N}_{2}$. Figure 6 presents the amount of coal saved in a year for a plaster coat having different insulation properties. Heating is provided by a boiler, the heating efficiency of which grows linearly with an increase in load, and for the sake of comparison, by a constant $80 \%$ efficiency boiler. The results refer there only to heat loss by conduction.

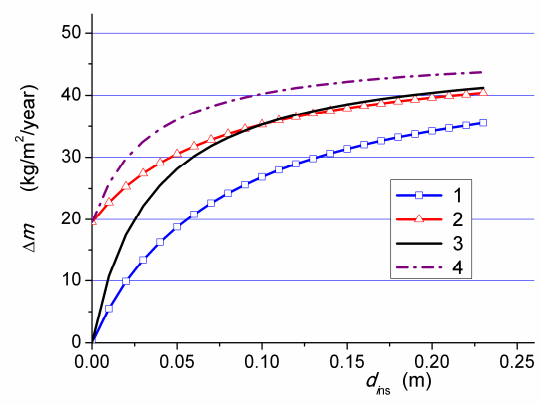

Fig. 6. Coal savings for plaster layers of different thickness 1 and $2-\lambda=0.15 \mathrm{~W} / \mathrm{mK}, 3$ and 4 $\lambda=0.067 \mathrm{~W} / \mathrm{mK}$, heating by boiler with load-regulated variable efficiency $(1,3)$, and with high, constant efficiency $(2,4)$.

The costs involved in the investment are mostly affected by the heat source that uses much fuel and has low efficiency. When thermo-modernisation of the building is planned, it is advisable to upgrade the heating system so that the boiler should have constant, and possibly high efficiency regardless of the actual demand for heat. If possible, the heating system upgrades should include hybrid or co-generation installations [16].

\section{Conclusions}

Thermo-modernisation of historic buildings requires particular diligence and generates high costs for the property owner. While seeking for possible solutions, it is essential to aim at minimum costs and maximum environmental effects that are of key importance for large, old cities. The application of heat-preserving plaster always leads to improvement in conditions and a reduction in operating costs. Depending on the plaster coat thickness that 
is possible to apply, more expensive material with better insulation parameters should be used for thinner coatings, whereas for thicker coatings, a cheaper material is acceptable (see Fig. 5). Thermo-modernisation of the building envelope offers an incentive to invest in heat source modernisation that always results in considerable costs reduction and enhancement of the environmental effect (see Fig. 6). Balancing the costs and benefits of the investment of that type is also related to weather risks. Depending on climatic conditions, weather risks can affect the profits from fuel savings, thus the expected return on the investment, as shown in Fig. 4.

Interference in the structure of the historic buildings is subject to special oversight under supervision of conservation officers. For this reason, the final selection of the thermomodernisation parameters should also take into account - if any - local and government regulation.

\section{References}

1. Ü. Alev, L. Eskola, E. Arumägi, J. Jokisalo, A. Donarelli, K. Siren, T. Broström, T. Kalamees, Energ. Buildings 77, 58 (2014)

2. K. Fabbri, Cult. Heritage 14S, 25 (2013)

3. S. Schiavoni, F. D'Alessandro, F. Bianchi, F. Asdrubali, Renew. Sust. Energ. Rev. 62, 988 (2016)

4. Z. Ma, P. Cooper, D. Daly, L. Ledo, Energ. Buildings 55, 889 (2012)

5. Z. Owsiak, W. Grzmil, J .Civil Eng. KSCE 1 (2014)

6. Z. Owsiak, J. Zapała-Sławeta, P. Czapik, B. Pol. Acad. Sci. Tech. Ser. 63-1, 23 (2015)

7. R. Cantin, J. Burgholzer, G. Guarracino, B. Moujalled, S. Tamelikecht, B.G. Royet, Build. Environ. 45, 473 (2010)

8. R. Dylewski, J. Adamczyk, Build. Environ. 46, 2615 (2011)

9. M. Ozel, Appl. Energ. 88, 2429 (2011)

10. T. Orzechowski, COW 6/47, 229 (2016)

11. https://bip.um.katowice.pl/dokumenty/2015/3/20/1426859144.pdf (in Polish)

12. Collective work ed. by Gawlik, L., Coal for Poland's energy production over 2050 time horizon-analysis of scenarios (in Polish), Katowice (2013)

13. Local Data Bank. Warsaw: www.stat.gov.pl, last accessed June 2016

14. Degree-days: theory and application TM41:2006, (Chartered Inst. Build. Services Engineers -London)

15. J. Dopke, COW 5/45, 171 (2014)

16. W. Stanek, W. Gazda, W. Kostowski, Energy 92, 279 (2015) 